\title{
Cardiotoxicity of methamphetamine under stress conditions: Comparison of single dose and long-term use
}

\author{
MASAFUMI TOMITA ${ }^{1}$, TOSHIKO OKUYAMA ${ }^{1}$, HIRONOBU KATSUYAMA $^{2}$, YOKO WATANABE ${ }^{3}$, \\ KOTARO SHINONE $^{4}$, MASAYUKI NATA ${ }^{4}$ and TAKAKI ISHIKAWA ${ }^{5}$ \\ Departments of ${ }^{1}$ Medical Toxicology, ${ }^{2}$ Public Health and ${ }^{3}$ Natural Sciences, Kawasaki Medical School, \\ Kurashiki 701-0192; ${ }^{4}$ Department of Forensic Medicine and Sciences, Mie University School of Medicine, \\ Tsu 514-8507; ${ }^{5}$ Department of Legal Medicine, Osaka City University Medical School, Osaka 545-8585, Japan
}

Received December 13, 2012; Accepted March 11, 2013

DOI: $10.3892 / \mathrm{mmr} .2013 .1408$

\begin{abstract}
Methamphetamine (METH) abuse continues to be a worldwide problem, damaging the myocardial tissues, as well as the brains of individual users. In addition, stressors that increase drug cravings also contribute to cardiovascular diseases. The aim of the present study was to examine the myocardial effects of METH, including METH-stress interactions and particularly, the effect of METH RNA expression in the heart. The study also aimed to compare single dose (acute) and long-term (chronic) treatments. Mice were divided into the control (C), METH injection (M), stress exposure (S) and METH plus stress (MS) groups and subjected to an acute water-immersion restraint stress or a mixed chronic stress composed of restraint, electric foot-shock and temperature change. METH was injected at $30 \mathrm{mg} / \mathrm{kg}$ (the acute study) or $10 \mathrm{mg} / \mathrm{kg}$ intraperitoneally (i.p.) three times per week (the chronic study). The results demonstrated that METH induced more deleterious effects in the myocardial tissues during acute and chronic administrations when under stress conditions. Heat shock proteins (Hsps) played a critical role in the acute phase, while numerous genes, including anti-oxidant, anti-apoptotic and physiological function genes, played significant roles in the chronic phase. These results indicate that METH abuse, ranging from episodes of binge abuse to chronic abuse over several years, may cause severe myocardial damage in human users under stress.
\end{abstract}

\section{Introduction}

Methamphetamine (METH) possesses a high potential for abuse and addiction and has become a serious social problem worldwide $(1,2)$. In Japan, the number of individuals arrested

Correspondence to: Professor Masafumi Tomita, Department of Medical Toxicology, Kawasaki Medical School, Matsushima 577, Kurashiki, Okayama 701-0192, Japan

E-mail: toxicology@med.kawasaki-m.ac.jp

Key words: methamphetamine, cardiotoxicity, stress, RNA expression, mice per year for METH abuse has been recorded as $>10,000$ for the last several decades (3). The cardiotoxic effect of METH is particularly dangerous as the drug accelerates the heart rate and elevates the blood pressure, which may cause cardiovascular collapse, resulting in not only acute METH poisoning, but also METH-induced sudden mortality (4,5). An increasing number of clinical and autopsy studies associate the use of METH with angina, tachycardia, hypertension, myocarditis, dilated cardiomyopathy, arrhythmia and sudden death $(5,6)$. However, stressors also increase the heart rate and catecholamine release and affect the hypothalamic-pituitary-adrenal axis $(7,8)$. Abnormal stress-induced activation of the sympathetic nervous system exacerbates heart failure (9). Even mental stressors in daily life are able to more than double the risk of subsequent myocardial ischemia (10). In addition, stressors increase drug-seeking or -taking behavior. Exposing laboratory animals to stress conditions increases the self-administration of psychostimulants, including amphetamine and cocaine $(11,12)$. In humans, clinical and laboratory studies have also indicated that stressors increase drug use (13-15). Thus, stress-drug interactions would increase the likelihood of consuming more drugs and play a significant role in the induction and development of cardiovascular diseases. Moreover, a recent study on humans has shown that stressors are able to alter subjective responses, including the heart rate, to a known drug of abuse (16). Söderpalm et al (17) demonstrated that acute stressors dampened the subjective responses to a low dose of METH in healthy volunteers, but that these effects were short-lived. Stratton et al studied cases of excited delirium leading to sudden mortality subsequent to a struggle and physical restraint and suggested the possibility that restraint stress exacerbated the cardiac damage caused by the stimulant drugs (18). A study by Uemura et al reported cases of sudden death during restraint that showed cardiac abnormalities (19). Although the causal mechanisms remain unknown, subjective responses to an illicit drug may be further sensitized under acute or chronic stress conditions.

Abuse of METH ranges from episodes of binge abuse to chronic abuse over several years. We previously examined the acute effect of METH on myocardial tissues and showed that METH-stress interactions affected the induction of heat shock proteins (Hsps), followed by an increased susceptibility of the hosts to cardiotoxicity due to the stimulant drug (20). In the 
present study, the effects of METH, including the METH-stress interactions, were investigated in the myocardium and the results of acute and chronic treatments were compared.

\section{Materials and methods}

Chemicals. The methamphetamine (METH) was purchased from Dainippon Sumitomo Pharma Co., Ltd. (Osaka, Japan). The drug was dissolved in $0.9 \%$ saline immediately prior to use. The chemicals and other solutions used were all of analytical grade.

Animals. Male C57BL/6J mice (8-9 weeks old) were obtained from CLEA Japan, Inc. (Tokyo, Japan). In total, 4-5 mice were housed in each polycarbonate cage and maintained in a controlled environment at $23 \pm 1^{\circ} \mathrm{C}$, with a 12 -h light/ dark cycle. The mice had free access to commercial rodent mouse feed (MF) pellets (Oriental Yeast, Tokyo, Japan) and tap water. All the experiments were approved by the Animal Research Committee (No. 11-030) of the Kawasaki Medical School, Japan.

Experimental protocol. The animals were divided into the control (C), METH (M), stress (S) and METH plus stress (MS) groups. The animals in the $\mathrm{S}$ and MS groups were exposed to water-immersion restraint stress for $6 \mathrm{~h}$ (the acute study) or to varied stressors for 4 weeks (the chronic study). The chronic stress program was as follows: Monday, a temperature change from 4 to $25^{\circ} \mathrm{C} / 1 \mathrm{~h}$ for $6 \mathrm{~h}$; Tuesday, electric foot shock (0.4-0.8 $\mathrm{mA}$ for $5 \mathrm{sec}$ at $30 \mathrm{sec}$ intervals for $30 \mathrm{~min}$ ) followed by a temperature change for $4 \mathrm{~h}$; Wednesday, temperature change under restraint stress for $6 \mathrm{~h}$; Thursday, temperature change for $6 \mathrm{~h}$; and Friday, water-immersion restraint stress for $3 \mathrm{~h}$. Just prior to the stress exposure, the METH was injected intraperitoneally (i.p.) at a dose of $30 \mathrm{mg} / \mathrm{kg}$ for the acute study or $10 \mathrm{mg} / \mathrm{kg} 3$ times per week (Monday, Wednesday and Friday) for the chronic study. The animals in the $\mathrm{C}$ and $\mathrm{M}$ groups received saline or METH in the same manner. The mice were sacrificed by cervical dislocation at the end of the treatment and blood was drawn directly from the heart. The serum obtained was stored at $-80^{\circ} \mathrm{C}$ until analysis. The hearts were removed for biochemical estimations.

Histological analysis. Blocks of ventricular tissue were fixed in $10 \%$ neutral-buffered formalin immediately subsequent to removal, processed using routine histology methods, paraffin-embedded, sliced into $5-\mu \mathrm{m}$ sections and stained with Azan Mallory stain. An independent observer who was blinded to the treatment examined the sections.

Assays of serum interleukin- 6 and corticosterone. The interleukin-6 (IL-6) and corticosterone levels were determined using commercial ELISA (Invitrogen, Carlsbad, CA, USA) and EIA kits (Yanaihara, Shizuoka, Japan), respectively, according to the manufacturers' instructions.

Quantitative analysis of the mRNA. The total RNAs were isolated from the ventricular tissues stabilized with RNA using an RNeasy mini kit (Qiagen, Hilden, Germany) according to the manufacturer's instructions. The residual
DNA was removed by DNase digestion. The concentration and purity of the total RNA that was obtained were determined by absorbance at 260/280 $\mathrm{nm}$ using a UV spectrophotometer (Beckman DU640). Reverse transcription was performed using $1 \mu \mathrm{g}$ total RNA and an Advantage RT-for-PCR kit (Clontech, Palo Alto, CA, USA) with an oligo (dT) $)_{18}$ primer.

Real-time PCR was conducted on the cDNAs from each individual animal using a SYBR-Green QPCR Master Mix (Stratagene, Agilent Technologies, Santa Clara, CA, USA) and synthetic gene-specific primer sets that were designed based on the sequences deposited in the NCBI GenBank database. $\beta$-actin was used as an endogenous control. A standard curve was employed to quantify the results of the real-time PCR.

Statistical analysis. Statistical analyses were carried out using JMP software (version 8.0). The results were expressed as the mean \pm SD and analyzed using a one-way analysis of variance, followed by Tukey's HSD test for multiple comparisons. $\mathrm{P}<0.05$ or $\mathrm{P}<0.01$ were considered to indicate statistically significant differences.

\section{Results}

Histological examination of chronically treated cardiac muscle. Although there was no increase in the collagenous fiber levels, hypercontraction, severe coagulation necrosis and ischemia were observed in the mice of the chronically treated MS group. By contrast, the damage was restricted to cytoplasmic eosinophilia, early ischemia and limited hypercontraction in the mice of the $\mathrm{M}$ and $\mathrm{S}$ groups. Fig. 1 shows the hypercontraction of the tissues of a chronically treated mouse. These results were in agreement with those obtained in the acute study (20), although the severity was increased by repeated treatment.

IL-6 and corticosterone levels of chronically treated mice. IL-6 levels in the serum of the chronically treated mice were then determined. The IL-6 levels were significantly increased under MS conditions, but not in the $\mathrm{M}$ or $\mathrm{S}$ group (Fig. 2A). This result was the same as the change observed in the mice subjected to the acute treatment; the IL-6 level in the MS group was higher than that in the $\mathrm{M}$ and $\mathrm{S}$ groups (20). Moreover, in the chronic study, a significant increase was obtained in the IL-6 RNA expression in the myocardial tissues of the MS group, but not in the $\mathrm{M}$ or $\mathrm{S}$ groups (Fig. 2B). However, the serum corticosterone levels differed in the acute and chronic treatments. The levels in the acute study were increased equally by M, S or MS conditions, whereas the levels in the chronic study were increased only by exposure to stressors, but not by the repeated injection of METH in the M and MS group (Fig. 3).

RNA expression. Table I summarizes the RNA expression at $3 \mathrm{~h}$ subsequent to the injection of $30 \mathrm{mg} / \mathrm{kg} \mathrm{METH}$ (the acute study) and the expression subsequent to one-month of treatment with $10 \mathrm{mg} / \mathrm{kg} \mathrm{METH}$ (the chronic study), with or without the stress conditions. As described previously (20), the increase in the expression of the heat shock proteins (Hsps), particularly Hsp70, in the $\mathbf{M}$ group was marked in the acute study, while the stimulation was lower during the one-month treatment. The RNA expression of the Hsps, including Hsp70, in the $\mathrm{M}$ group showed a tendency to increase subsequent to the 
Table I. Comparison of RNA expression.

\begin{tabular}{|c|c|c|c|c|c|c|}
\hline \multirow[b]{2}{*}{ Gene } & \multicolumn{3}{|c|}{ One dose of METH $(30 \mathrm{mg} / \mathrm{kg})$} & \multicolumn{3}{|c|}{ One-month treatment with METH $(10 \mathrm{mg} / \mathrm{kg})$} \\
\hline & M & $\mathrm{S}$ & MS & M & $S$ & MS \\
\hline Hsp60 & $181.48 \pm 56.36^{\mathrm{a}}$ & $93.23 \pm 11.18$ & $90.89 \pm 11.94$ & $131.58 \pm 19.15$ & $85.75 \pm 13.45$ & $94.01 \pm 11.81$ \\
\hline Hsp70 & $2422.86 \pm 996.80^{\mathrm{a}}$ & $189.35 \pm 164.71$ & $191.1 \pm 96.42$ & $254.42 \pm 132.96^{\mathrm{b}}$ & $111.02 \pm 8.25$ & $127.21 \pm 45.72$ \\
\hline Hsp90 & $402.78 \pm 332.74^{\mathrm{a}}$ & $129.51 \pm 26.56$ & $101.54 \pm 19.84$ & $138.08 \pm 35.05$ & $99.48 \pm 16.48$ & $96.46 \pm 7.15$ \\
\hline MT1 & $269.94 \pm 92.49^{\mathrm{a}}$ & $130.57 \pm 28.55$ & $122.55 \pm 41.11$ & $125.73 \pm 31.85$ & $159.84 \pm 32.98$ & $186.6 \pm 66.16^{\mathrm{b}}$ \\
\hline MT2 & $668.12 \pm 290.67^{\mathrm{a}}$ & $407.16 \pm 146.6^{\mathrm{b}}$ & $302.3 \pm 127.02$ & $115.39 \pm 44.86$ & $312.85 \pm 61.88^{\mathrm{b}}$ & $427.21 \pm 212.13$ \\
\hline Prdx 1 & $98.21 \pm 30.03$ & $81.69 \pm 32.39$ & $68.43 \pm 20.2$ & $121.7 \pm 32.11$ & $75.98 \pm 14.24$ & $96.14 \pm 21.4$ \\
\hline Gcs & $123.3 \pm 29.48$ & $101.32 \pm 28.41$ & $87.26 \pm 18.59$ & $127.06 \pm 24.11$ & $105.88 \pm 16.64$ & $102.94 \pm 17.85$ \\
\hline Sod2 & $108.6 \pm 23.66$ & $98.3 \pm 14.94$ & $110.38 \pm 40.92$ & $167.85 \pm 20.88^{a}$ & $127.98 \pm 22.84$ & $150.58 \pm 12.76^{a}$ \\
\hline Catalase & $121.27 \pm 29.99$ & $91.93 \pm 32.62$ & $87.88 \pm 21.58$ & $136.41 \pm 11.37^{\mathrm{a}}$ & $94.37 \pm 12.81$ & $114.92 \pm 11.79$ \\
\hline Gpx1 & $96.89 \pm 27.25$ & $127.56 \pm 40.2$ & $94.59 \pm 44.62$ & $115.41 \pm 10.97$ & $104.92 \pm 19.12$ & $139.34 \pm 17.25^{\mathrm{a}}$ \\
\hline GST & $86.51 \pm 35.11$ & $102.26 \pm 40.07$ & $95.37 \pm 38$ & $298.75 \pm 47.06^{\mathrm{a}}$ & $240.00 \pm 50.12^{\mathrm{a}}$ & $323.44 \pm 74.19^{\mathrm{a}}$ \\
\hline iNOS & $48.92 \pm 19.25^{\mathrm{a}}$ & $54.53 \pm 8.04^{\mathrm{a}}$ & $61.13 \pm 8.31^{\mathrm{a}}$ & $98.36 \pm 18.08$ & $57.4 \pm 18.02^{\mathrm{a}}$ & $50.45 \pm 12.55^{\mathrm{a}}$ \\
\hline ACE & $104.22 \pm 26.11$ & $59.85 \pm 23.42^{b}$ & $92.56 \pm 46.19$ & $150.52 \pm 16.23$ & $131.83 \pm 23.57$ & $172.49 \pm 46.38^{b}$ \\
\hline PGI2 synthase & $119.89 \pm 23.79$ & $92.06 \pm 14.68$ & $101.28 \pm 28.59$ & $170.4 \pm 37.37$ & $194.4 \pm 42.76^{\mathrm{b}}$ & $201 \pm 43.13^{\mathrm{b}}$ \\
\hline IP & $96.65 \pm 34.42$ & $51.43 \pm 10.02^{\mathrm{a}}$ & $61.49 \pm 24.24^{\mathrm{b}}$ & $176.97 \pm 17.88^{\mathrm{a}}$ & $90.91 \pm 22.68$ & $112.12 \pm 3.5$ \\
\hline $\mathrm{Bcl} 2$ & $76.29 \pm 24.99$ & $73.58 \pm 23.46$ & $72.25 \pm 18.85$ & $140 \pm 25.56^{\mathrm{b}}$ & $108.57 \pm 23.9$ & $75 \pm 7.14$ \\
\hline Pgk1 & $97.03 \pm 21.6$ & $86.1 \pm 12.24$ & $80.27 \pm 21.42$ & $183.83 \pm 24.52^{\mathrm{a}}$ & $137.87 \pm 25.1$ & $129.79 \pm 22.38$ \\
\hline PLTP & $78.07 \pm 26.5$ & $65.87 \pm 13.3^{\mathrm{b}}$ & $73.95 \pm 18.81$ & $117.5 \pm 6.85$ & $100 \pm 15.31$ & $140.63 \pm 18.75^{\mathrm{a}}$ \\
\hline
\end{tabular}

Data are presented as the mean \pm SD. METH, methamphetamine; M, METH injection group; S, stress exposure group; MS, METH plus stress group; Hsp, heat shock protein; MT, methallothionein; Gcs, glucocorticosteroids; Sod, superoxide dismutase; Gpx, glutathione peroxidase; GST, glutathione S-transferase; iNOS, inducible nitric oxide synthase; ACE, angiotensin-converting enzyme; PGI2, prostacyclin; IP, prostacyclin receptor; Bcl, B-cell lymphoma; Pgk, phosphoglycerate kinase; PLTP, plasma phospholipid transfer protein; SD, standard deviation. ${ }^{a} \mathrm{P}<0.01$ and ${ }^{b} \mathrm{P}<0.05$ vs. the control value of 100 .
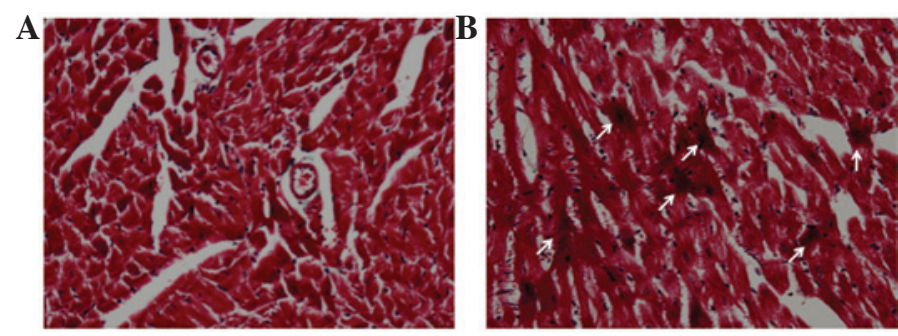

Figure 1. Histological examination of the chronically treated cardiac muscle. (A) Control. (B) Hypercontraction in the MS group (arrows). Azan Mallory stain, magnification x200. MS, Methamphetamine plus stress.

one-month treatment, but the upregulation was not comparable to the increase due to the acute treatment. The RNA expression for methallothionein (MT) also differed in the acute and chronic treatments. The expression increased markedly in the $\mathrm{M}$ group of the acute study, whereas in the chronic study, the increase was more marked in the S and MS groups. The RNA expression of the other anti-oxidant enzymes, including superoxide dismutase 2 (Sod2), catalase, glutathione peroxidase 1 (Gpx1) and glutathione S-transferase (GST), was examined. The expression of these enzymes was significantly increased in the M, S and/or MS groups by the chronic treatment, but not by the acute treatment.

The RNA expression for inducible nitric oxide synthase (iNOS) decreased in the M,S and MS groups of the acute study, while, for the one-month treatment, a significant decrease was observed in the $\mathrm{S}$ and MS groups, but not in the M group. The level in the $\mathrm{M}$ group was the same as the control level. Moreover, the angiotensin-converting enzyme (ACE) RNA expression increased subsequent to the chronic treatment and showed a significant increase under the METH plus stress conditions.

The RNA expression for prostacyclin (PGI2) synthase increased in the chronic treatment group, but not in the acute study group. The RNA expression for the prostacyclin receptor, $\mathrm{IP}$, however, showed a significant increase only in the $\mathrm{M}$ group subjected to chronic treatment. Moreover, a significant increase was obtained in the RNA expression of the anti-apoptosis factor, B-cell lymphoma-2 (Bcl2), and the ATP-generating enzyme of glycolysis, phosphoglycerate kinase 1 (Pgk1), but only in the $\mathrm{M}$ group treated for one month. In addition, the RNA expression of the plasma phospholipid transfer protein (PLTP), which 

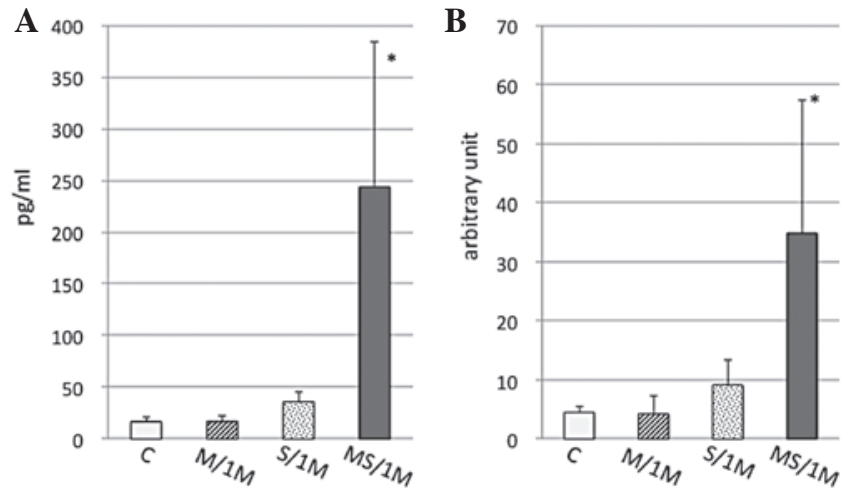

Figure 2. (A) IL-6 levels in the serum. (B) IL-6 RNA expression in the cardiac muscle. The mice were treated for one month $(1 \mathrm{M}) .{ }^{*} \mathrm{P}<0.01 \mathrm{vs}$. control value. IL-6, interleukin-6; C, control group; $\mathrm{M}$, methamphetamine injection group; S, stress exposure group; MS, methamphetamine plus stress group.

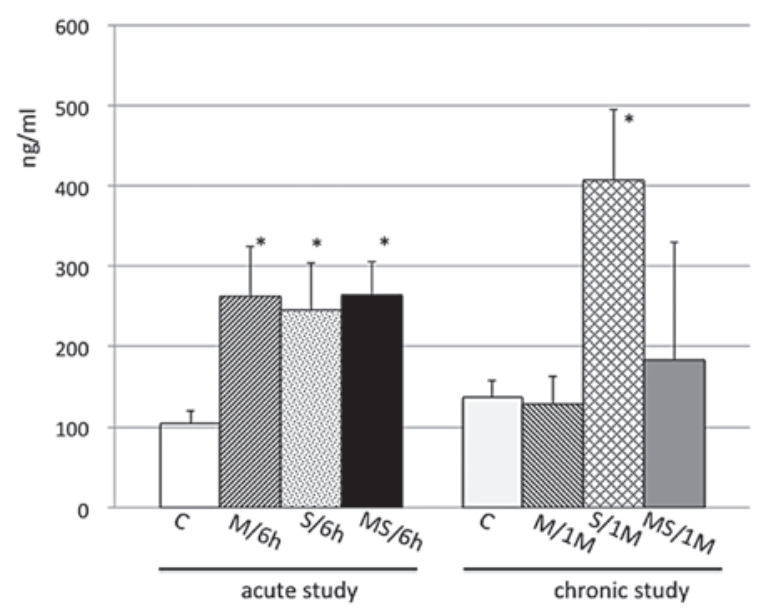

Figure 3. Corticosterone levels in serum of mice treated acutely (6h) or chronically (one month: $1 \mathrm{M}$ ). " $\mathrm{P}<0.01$ vs. control value. C, control group; $\mathrm{M}$, methamphetamine injection group; $\mathrm{S}$, stress exposure group; MS, methamphetamine plus stress group.

is related to the development of atherosclerosis, significantly increased in the MS group following the chronic treatment.

\section{Discussion}

In a previous study focusing on Hsps, acute stress depressed the induction of the Hsps due to the METH and was followed by enhanced METH-induced myocardial damage (20). In the present study, M, S or MS-induced cardiotoxicity were examined and compared subsequent to acute and chronic treatments. The histological results from the myocardium subsequent to the chronic treatment showed more severe damage in the mice of the MS group than the M or S group. In addition, the serum IL-6 level was markedly increased in the MS group (Fig. 2A). Elevated serum IL-6 levels suggest that IL-6 may play a significant role in the pathogenesis of heart disease, as described in a previous study (21). Although IL-6 is secreted by various types of cells $(22,23)$, an increase in the RNA expression in the myocardial tissues of the present study (Fig. 2B) indicated that an increase in the IL-6 in the heart may in part account for the elevated serum levels. The histological findings and the increase in IL-6 observed in the chronically treated MS group indicated that more severe injuries may occur in the myocardial tissues under MS conditions. These results obtained from the chronic study were almost the same as those obtained from the acute experiment (20). By contrast, the corticosterone levels subsequent to the one-month treatment differed from those of the acute study. The levels in the $\mathrm{M}, \mathrm{S}$ and $\mathrm{MS}$ groups were equally increased in the acute study, whereas the levels in the chronic study were increased only by exposure to stressors and not by repeated injections of METH (Fig. 3). Thus, METH may have had some effect on the corticosterone release during the one-month treatment.

The expression of numerous genes is supposed to be increased or decreased in the cardiac myocytes as a result of METH injections administered with or without stress, but the dynamic phase of these genes has not been elucidated. The effect on the Hsps was prominent in the acute treatment in the present study. Upregulation, particularly of Hsp70, was markedly elicited by METH in the acute study, whereas its expression was limited to only a mild tendency to increase in the chronic study. MT also showed differing effects in the two regimens; stimulation in the $\mathrm{M}$ group following the acute treatment, but in the S and MS groups following the chronic treatment. MT exists in the majority of organs, including animal and human hearts, and is inducible to a high level by various oxidative or pathogenic stresses (24). The induction of cardiac MT by various agents was previously shown to significantly prevent oxidative damage in hearts (25). Other investigators have suggested that oxidation of the myocardial proteins contributes to the heart's dysfunction (26). In the present study, anti-oxidant enzymes, including Sod2, catalase, Gpx1 and GST, were significantly increased by the chronic, but not by the acute treatment. These findings suggested that oxidative stress may play a significant role in the cardiac damage caused by the chronic treatment.

One NOS isoform, iNOS, is expressed in a wide variety of cell types, including cardiac myocytes and cardiac endothelial cells, in response to certain stimuli, including hypoxia (27). The inhibition of iNOS raises the peroxidative and apoptotic level in the hypoxic heart, indicating that this isoform may protect the organ from hypoxia/reoxygenation injuries (28). In the present study, only the chronically treated $\mathrm{M}$ group retained the basal iNOS level, while the expression levels in the remaining groups were downregulated. ACE has angiotensin II-dependent and -independent effects on cardiovascular function and is a logical target for the regulation of the renin-angiotensin system. Specifically, ACE inhibition reduces blood pressure, left ventricular hypertrophy and cardiac inflammation in spontaneously hypertensive rats (29). Clinical studies have shown that various ACE inhibitors are effective in the treatment of congestive heart failure, acute myocardial infarction, coronary artery disease and hypertension (30). As shown in Table I, the present study suggested that the upregulation of ACE in the chronic treatment caused serious cardiac damage, particularly when under METH plus stress conditions. Prostacyclin also has vasodilatory and anti-thrombotic properties, showing multiple cardiovascular protective actions by the activation of its $\mathrm{G}$ protein-coupled receptor, IP (31). Although the RNA expression for PGI2 synthase was increased by the chronic treatment and not by the acute treatment, the expression for its receptor, 
IP, was significantly increased only in the chronically treated M group. This suggested that the PGI2/IP pathway was effective only in the mice of the $\mathrm{M}$ group that were treated for one month.

Injections of METH for one month increased the RNA expression of $\mathrm{Bcl} 2$, a well-known anti-apoptosis factor. The upregulation of Bcl-2 significantly inhibited the extent of the apoptosis of the cardiomyocytes induced by ischemia/ reperfusion (32), suggesting that $\mathrm{Bcl}-2$ was able to protect the cardiomyocytes. In addition, a significant increase was observed in the Pgk1 expression in the M group subjected to the chronic treatment. This result supports an adaptive response to hypoxia that underlies the cellular and systemic oxygen homeostasis in the mice of this group (33). By contrast, PLTP is a significant modulator of the phospholipid transfer and exchange among the proteins and also plays a role in inflammation and oxidative stress (34). The PLTP activity is likely a novel marker for the systolic dysfunction of the left ventricle in patients with known or suspected coronary artery disease (35). Upregulation of the PLTP expression was observed in the chronically treated MS group, suggesting that the mice in this group were at risk of developing atherosclerosis. Taken together, these RNA expression results indicated that METH intake under stress conditions enhanced cardiotoxicity in short- and long-term abuse.

In conclusion, METH induced more deleterious effects in the myocardial tissues of the acute and chronic studies when subjected to stress conditions, even when the level of stress hormone was lowered to the basal level. The Hsps play a critical role in the acute phase, while a number of genes, including anti-oxidant, anti-apoptotic and physiological functional genes, are involved in the chronic phase. Stressors increase drug cravings in humans and METH-induced myocardial toxicity would be a severely deleterious event.

\section{Acknowledgements}

The authors would like to thank Mr. N. Iwachidou and Ms.E.Ohtsuki for their excellenttechnical assistance in preparing the tissue sections. This study was supported by Grants-in-Aid for Scientific Research (KAKENHI; No. 22590644).

\section{References}

1. Brecht ML, von Mayrhauser C and Anglin MD: Predictors of relapse after treatment for methamphetamine use. J Psychoactive Drugs 32: 211-220, 2000.

2. Comer SD, Hart CL, Ward AS, Haney M, Foltin RW and Fischman MW: Effects of repeated oral methamphetamine administration in humans. Psychopharmacology (Berl) 155: 397-404, 2001

3. Wada K: The history and current state of drug abuse in Japan. Ann NY Acad Sci 1216: 62-72, 2011.

4. Saito T, Takeichi S, Nakajima Y, Yukawa N and Osawa M: Fatal methamphetamine poisoning in police custody. J Clin Forensic Med 3: 183-185, 1996.

5. Inoue H, Ikeda N, Kudo K, Ishida T, Terada M and Matoba R: Methamphetamine-related sudden death with a concentration which was of a 'toxic level'. Leg Med (Tokyo) 8: 150-155, 2006.

6. Wijetunga M, Seto T, Lindsay J and Schatz I: Crystal methamphetamine-associated cardiomyopathy: tip of the iceberg? J Toxicol Clin Toxicol 41: 981-986, 2003.

7. Tsigos C and Chrousos GP: Hypothalamic-pituitary-adrenal axis, neuroendocrine factors and stress. J Psychosom Res 53 865-871, 2002.

8. Miller GE, Chen E and Zhou ES: If it goes up, must it come down? Chronic stress and the hypothalamic-pituitary-adrenocortical axis in humans. Psychol Bull 133: 25-45, 2007.
9. Kishi T: Heart failure as an autonomic nervous system dysfunction. J Cardiology 59: 117-122, 2012.

10. Pickering TG: Does psychological stress contribute to the development of hypertension and coronary heart disease? Eur J Clin Pharmacol 39 (Suppl 1): S1-S7, 1990.

11. Tidey JW and Miczek KA: Acquisition of cocaine self-administration after social stress: role of accumbens dopamine. Psychopharmacology (Berl) 130: 203-212, 1997.

12. Piazza PV and Le Moal M: The role of stress in drug self-administration. Trends Pharmacol Sci 19: 67-74, 1998.

13. Perkins KA and Grobe JE: Increased desire to smoke during acute stress. Br J Addict 87: 1037-1040, 1992.

14. Sinha R: How does stress increase risk of drug abuse and relapse? Psychopharmacology (Berl) 158: 343-359, 2001.

15. Sinha R, Catapano D and O'Malley S: Stress-induced craving and stress response in cocaine dependent individuals. Psychopharmacology (Berl) 142: 343-351, 1999.

16. Zhao LY, Shi J,Zhang XL and Lu L: Psychosocial stress enhances non-drug-related positive memory retrieval in male abstinent heroin addicts. Neurosci Lett 485: 16-20, 2010.

17. Söderpalm AH, Nikolayev L and de Wit H: Effects of stress on responses to methamphetamine in humans. Psychopharmacology (Berl) 170: 188-199, 2003.

18. Stratton SJ, Rogers C, Brickett K and Gruzinski G: Factors associated with sudden death of individuals requiring restraint for excited delirium. Am J Emerg Med 19: 187-191, 2001.

19. Uemura K, Ueyama T, Shintani-Ishida K, Unuma K and Yoshida K: An autopsy report on four sudden cardiac death cases by immobilization. Int Med J 15: 301-305, 2008.

20. Tomita M, Katsuyama H, Watanabe Y, et al: Water-restraint stress enhances methamphetamine-induced cardiotoxicity. Chem Biol Interact 190: 54-61, 2011.

21. Ikeda U, Ohkawa F, Seino Y, et al: Serum interleukin 6 levels become elevated in acute myocardial infarction. J Mol Cell Cardiol 24: 579-84, 1992.

22. Jirik FR, Podor TJ, Hirano T, et al: Bacterial lipopolysaccharide and inflammatory mediators augment IL- 6 secretion by human endothelial cells. J Immunol 142: 144-147, 1989.

23. Yamauchi-Takihara K, Ihara Y, Ogata A, Yoshizaki K, Azuma J and Kishimoto T: Hypoxic stress induces cardiac myocyte-derived interleukin-6. Circulation 91: 1520-1524, 1995.

24. Kang YJ: The antioxidant function of metallothionein in the heart. Proc Soc Exp Biol Med 222: 263-273, 1999.

25. Nath R, Kumar D, Li T and Singal PK: Metallothioneins, oxidative stress and the cardiovascular system. Toxicology 155: 17-26, 2000.

26. Canton M, Menazza S, Sheeran FL, Polverino de Laureto P, Di Lisa F and Pepe SP: Oxidation of myofibrillar proteins in human heart failure. J Am Coll Cardiol 57: 300-309, 2011.

27. Jung F, Palmer LA, Zhou N and Johns RA: Hypoxic regulation of inducible nitric oxide synthase via hypoxia inducible factor-1 in cardiac myocytes. Circ Res 86: 319-325, 2000.

28. Rus A, del Moral ML, Molina F and Peinado MA: Does inducible NOS have a protective role against hypoxia/reoxygenation injury in rat heart? Cardiovasc Pathol 20: e17-e25, 2011.

29. Miguel-Carrasco JL, Zambrano S, Blanca AJ, et al: Captopril reduces cardiac inflammatory markers in spontaneously hypertensive rats by inactivation of NF-kB. J Inflamm (Lond) 7: 21, 2010.

30. Katragadda S and Arora RR: Role of angiotensin-converting enzyme inhibitors in vascular modulation: beyond the hypertensive effects. Am J Ther 17: e11-e23, 2010.

31. Chan EC, Dusting GJ, Guo N, et al: Prostacyclin receptor suppresses cardiac fibrosis: role of CREB phosphorylation. J Mol Cell Cardiol 49: 176-185, 2010.

32. Maulik N, Engelman RM, Rousou JA, Flack JE III, Deaton D and Das DK: Ischemic preconditioning reduces apoptosis by upregulating anti-death gene Bcl-2. Circulation 100 (19 Suppl): II369-II375, 1999.

33. Wu S, Storey JM and Storey KB: Phosphoglycerate kinase 1 expression responds to freezing, anoxia, and dehydration stresses in the freeze tolerant wood frog, Rana sylvatica. J Exp Zool A Ecol Genet Physiol 311: 57-67, 2009.

34. Jiang XC, Tall AR, Qin S, et al: Phospholipid transfer protein deficiency protects circulating lipoproteins from oxidation due to the enhanced accumulation of vitamin E. J Biol Chem 277: 31850-31856, 2002.

35. Cavusoglu E, Marmur JD, Chhabraa S, Choprab V, Eng C and Jiangc XC: Relation of baseline plasma phospholipid transfer protein (PLTP) activity to left ventricular systolic dysfunction in patients referred for coronary angiography. Atherosclerosis 207 : 261-265, 2009. 